\title{
Studying Flammability in a Commercial Transport Fuel Tank with Inerting
}

\author{
William M. Cavage \\ Steven M. Summer \\ FAA Airport and Aircraft Safety R\&D Division, William J. Hughes Technical Center \\ Robert I. Ochs \\ SRA International, Inc. \\ C. E. Polymeropoulos \\ Department of Mechanical and Aerospace Engineering, Rutgers, The State University of New Jersey
}

Copyright $@ 2005$ SAE International

\begin{abstract}
As part of the continued emphasis on fuel tank safety, the Federal Aviation Administration (FAA) has developed a demonstration fuel tank inerting system and has tested it on a NASA-operated Boeing 747 aircraft. To support this, the FAA developed two models to predict both fuel tank oxygen concentration and flammability in an inerted ullage, based on previously developed models and calculations. Laboratory and aircraft test results indicated that the models duplicated measured data trends well and gave predicted peak values with a reasonable degree of accuracy. This allowed the FAA to develop a representative Boeing 747 aircraft flight cycle and give predictions of flammability exposure for the given ullage. The results indicated that the aircraft fuel tank would not be exposed to flammable conditions during the developed flight profile with the represented inerting system even though part of the tank ullage did achieve oxygen concentration levels of approximately $18 \%$.
\end{abstract}

\section{INTRODUCTION}

The Federal Aviation Administration (FAA) has placed significant emphasis on fuel tank safety since the TWA Flight 800 accident in July 1996. Extensive development and analysis has shown that fuel tank inerting could potentially be cost-effective if air separation modules (ASMs), based on hollow-fiber membrane technology, could be used in an efficient manner to produce inert gas. To illustrate this, the FAA, with the assistance of several aviation-oriented companies, developed an onboard inert gas generation system (OBIGGS) that uses ASMs and aircraft bleed air to generate nitrogenenriched air (NEA) at varying flow and purity during a commercial airplane flight cycle. This system was tested and evaluated during a series of flight tests performed on a modified NASA-operated Boeing 747 aircraft for transporting the Space Shuttle Orbiter.

To support this research, the FAA Airport and Aircraft Safety R\&D Division, Fire Safety Branch has developed two analytical models: one to predict ullage oxygen concentration and one that predicts total hydrocarbon concentration (THC), given a set of inerting conditions, fuel properties, fuel tank temperatures, and a flight profile. The inerting model assumes perfect mixing, and calculates the mass of oxygen in and out of a set of generic, interconnected ullage volumes at a varying time step. The flammability model employs fuel evaporation and condensation calculations based on a generic fuel composition, and determines the ullage vapor content at homogeneous temperatures and then modifies that content with wall condensation effects. These models were validated with flight test data measured during evaluation flight tests of the FAA inerting system.

\section{PREVIOUS RESEARCH}

\section{Fuel Tank Flammability}

Previous research at the FAA concerning fuel tank flammability has focused largely on the Limiting Oxygen Concentration (LOC) of aviation-grade fuels. The LOC is defined as the oxygen concentration below which ignition of fuel vapors can no longer be supported. It is the main design criteria for any inerting system, as it determines the oxygen levels required to provide adequate fuel tank explosion protection. Military OBIGGS have been designed to $L O C$ values as low as $9 \% \mathrm{O}_{2}$. However, recent FAA studies [1] show that the sea level LOC for aviation-grade fuels, such as Jet $A$, used in commercial transport aircraft can be placed $33 \%$ higher at a value of $12 \% \mathrm{O}_{2}$. 


\section{Fuel Tank Ullage Modeling}

Previous fuel tank ullage modeling work was primarily performed by the United States Department of Defense to study the survivability of military aircraft. The most well known of these studies culminated in an extensive model of ullage gas composition, given a wide range of mission data, fuel data, and OBIGGS performance parameters [2]. This model was validated with a wide range of test data generated in a ground test facility designed to simulate an aircraft fuel tank ullage during various military aircraft flight profiles. The focus of the modeling research was to study ullage flammability and dissolved air evolution from fuel during particular military missions, and included the effect of tank slosh and vibration.

The FAA also developed a multiple-bay analytical model to study the capabilities and limitations of ground-based inerting. Comparisons of data obtained from a scale Boeing 747 center wing tank (CWT) replica and the multiple-bay analytical model data were made with fullscale ground inerting measurements and also with a computational fluid dynamics model developed by Boeing Phantom Works [3]. This reference illustrates the excellent agreement between ground inerting data on a Boeing 747SP ground test article and data obtained with the scale Boeing 747 CWT replica, compared to the multiple-bay analytical model.

\section{SCOPE}

This research paper will give comparisons of both the inerting and flammability model data with acquired flight test data and will illustrate the results of a modeling exercise that predicts the oxygen and THC concentrations in a multiple-bay, compartmentalized fuel tank for a generic proposed flight cycle and inerting system. The results of calculated flammability levels and exposure will also be presented.

\section{TEST ARTICLES}

\section{NASA 747 SCA TEST AIRCRAFT}

Flight tests of the FAA inerting system were performed in cooperation with NASA on their 747 SCA, which is a highly modified Boeing 747 used to carry the Space Shuttle Orbiter, to study the OBIGGS performance throughout typical flight conditions and to validate existing inerting models. Figure 1 shows a cut-a-way view of the immense Boeing 747 CWT, which is typical of all classic style Boeing 747 aircraft. The FAA OBIGGS was installed in the test aircraft pack bay area. The NEA from the system was deposited in bay 6 of the aircraft CWT with the right-hand side of the vent system blocked (see figure 2) to prevent cross-venting of the tank.

The primary instrumentation employed for the flight tests was the gas sample tubing in the CWT that allowed continuous oxygen concentration measurements at eight locations (see eight red circles in figure 2) using the FAA Onboard Oxygen Analysis System (OBOAS). The OBOAS is a specialized instrument that continuously measures the oxygen concentration in an aircraft fuel tank ullage using conventional oxygen analyzers (galvanic cell), a powerful diaphragm pump, and a pressure-regulated sample train [4]. Additionally, the inerting system NEA flow and purity were measured, as were a variety of system temperatures and pressures to analyze the system performance. Atmospheric pressure was also measured during the flight tests [5].

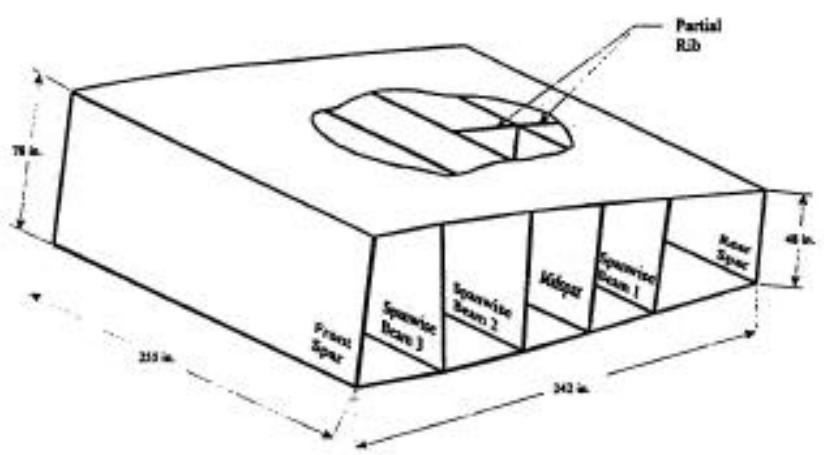

Figure 1: Boeing 747 Center Wing, Tank Cut-Away View

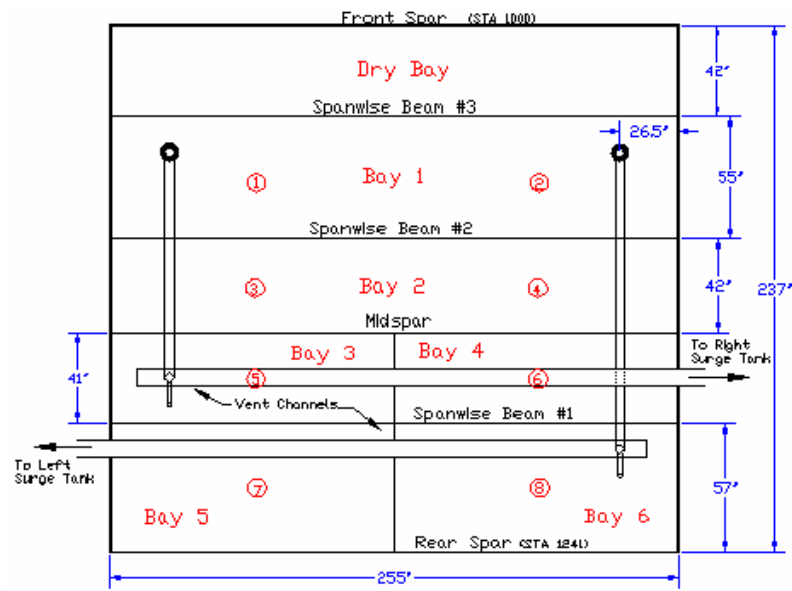

Figure 2: Top Diagram of the Boeing 747 CWT

\section{SCALE FUEL TANK FLAMMABILITY TEST ARTICLE}

The scale model flammability experiment cited in this work is described in greater detail in reference 6 . The rectangular fuel tank was constructed of $1 / 4$ ? aluminum metal sheets welded together with outer dimensions of 36 ? wide by 36 ? deep by 24 ? high. An access panel measuring 12 ? by 16 ? was located on the top surface to allow for thermocouple pass-thru, ullage sampling, and ullage venting. The simulated aircraft fuel tank was tested inside an environmental chamber with inner 
dimensions of $6^{\prime}$ wide by $6^{\prime}$ high by $8^{\prime}$ deep under varying ambient temperatures and pressures.

The environmental chamber had the capability of varying the temperature with a cascade-type air conditioning unit that could obtain temperatures as low as $-100^{\circ} \mathrm{F}$ and a vacuum pump that can decrease the pressure to about 2 psia. Twelve thermocouples were located in various places throughout the tank and chamber: four thermocouples were located in the liquid fuel, one of which was used by the heater temperature controller to maintain a specified liquid temperature; three more were located in the ullage; and one was in the ambient chamber air. A silicone rubber heating blanket measuring 36 ? $\times 36$ ? was mated to the bottom surface, which heated the tank and vaporized the fuel. THC within the ullage space was measured using a flame ionization detector hydrocarbon analyzer calibrated with propane gas.

\section{ANALYSIS}

\section{MULTIPLE-BAY ANALYTICAL INERTING MODEL}

To better understand the effect of some flight and system performance scenarios on the fuel tank inerting process, an analytical model was developed to calculate the ullage oxygen concentration in several connected bays of a fuel tank, given the specific tank bay volumes, starting oxygen concentration, and inerting system performance schedule. The performance schedule gives a mission time and altitude with the OBIGGS volume flow rate and purity (oxygen concentration). The model assumes the pressure inside the tank is equal to ambient pressure outside the aircraft and has ullage temperature as an input variable. This calculation is easy to envision for a simple cascading inerting process for $\mathrm{n}$ bays that receives inert gas in bay 1 and vents the mixed ullage out of the nth bay to atmospheric pressure P. Figure 3 illustrates the concept.

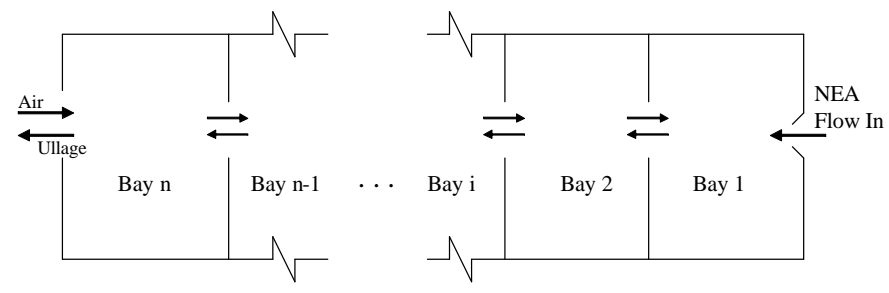

Figure 3: Diagram of Cascading Inerting a Tank With n Bays

To calculate the oxygen concentration in each bay for the cascading inerting case illustrated in figure 3 , the NEA volume flow and purity was first converted at each time step to a mass of oxygen deposited using the equation of state. The ullage mass of each bay is then tracked given the ullage density, knowing pressure, temperature, and the universal gas constant for air. Assuming no storage in the tank (tank pressure is always equal to atmospheric pressure), the changing mass of each bay is tracked in time as are any corresponding changes in the mass of oxygen in each bay. This is done given the individual bay volumes and starting oxygen concentration in each bay. The model tracks the change in mass of oxygen due to the addition of inert gas, the passing of mixed ullage gas from bay to bay, and the ventilation of ullage gas from the tank. The mass of ullage gas in each bay $(M)$ and the mass of oxygen in each bay $(M o)$ are tracked at each time step using the following general equations with the indice $i$ referring to the bay number.

$$
\begin{gathered}
M_{\mathrm{B} a y i}(t)=M_{\mathrm{B} a y i}(t-1)+\Delta M_{\text {ullage }} \\
M o_{\mathrm{B} a y i}(t)=M o_{\mathrm{B} a y i}(t-1)+M o_{\mathrm{Out}_{\mathrm{B} a y i}}(t)-M o_{\mathrm{Out}_{\mathrm{B} a y i+1}}(t)
\end{gathered}
$$

These equations allow for the fraction of oxygen (Fo) of the ullage gas in each bay to be calculated using the following equation.

$$
F O_{\text {Bay } i}=M o_{\text {Bayi }}(t) / M_{\text {Bayi }}(t)
$$

To calculate the inert gas distribution in terms of oxygen concentration within the six-bay center-wing fuel tank of a Boeing 747, the simple relationships of gas passing from one bay to another, developed for the cascading inerting case, had to be modified to a more complex relationship with certain bays receiving ullage gas from several other bays and ullage gas being vented from and receiving air into two different bays. Figure 4 shows a diagram of the assumed flow pattern for the six-bay CWT illustrated in figures 1 and 2 . Note the bay number convention is the same as in figure 2 and is not consistent with the bay numbering convention given for the cascading inerting explanation from figure 3 . Reference 7 gives a more complete discussion of the multiple-bay analytical inerting model as well as detailed calculations for cascading inerting.

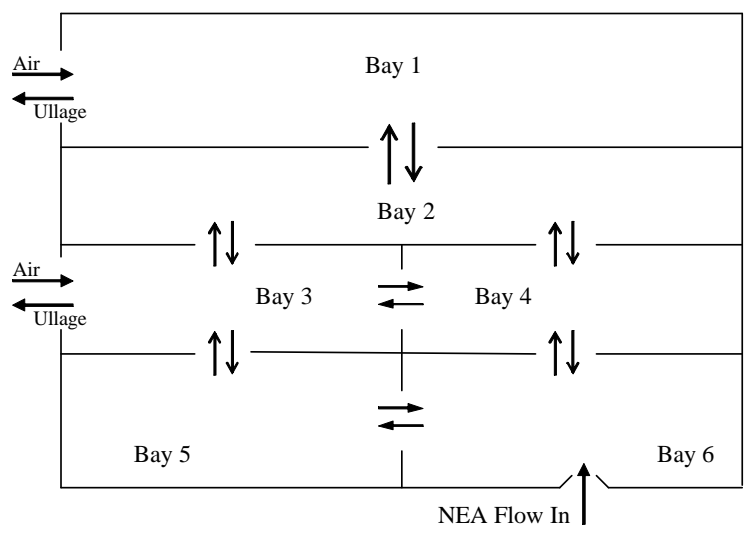

Figure 4: Analytical Multiple-Bay Inerting Model Assumed Flow Pattern 


\section{RESULTS}

A brief description of the vaporization model used in this study is discussed here, while a more thorough description is available in reference 8 . The model assumed that the flow field in the tank was driven by natural convection between the heated liquid fuel on the floor and the unheated ceiling and sidewalls. The gas within the tank ullage was considered to be well mixed, and the heat and mass transport within the tank was expressed using empirical heat transfer correlations and the analogy between heat and mass transfer for estimating film coefficients. The well-mixed assumption is justified because the natural convective flow in the tank was in the turbulent region, since the magnitude of the Rayleigh number based on the floor-to-ceiling temperature difference and the tank height is typically of the order of $10^{9}$.

The model considers multiple component jet fuel as the evaporating liquid. The fuel composition was obtained from literature [9], where liquid fuel samples with a range of flash points $\left(100^{\circ}\right.$ to $\left.140^{\circ} \mathrm{F}\right)$ were characterized by gas chromatographic analysis in terms of mole fractions of C5-C20 normal alkanes. In addition to vaporization of the fuel on the tank floor, the model determines condensation of vapor species on the tank ceiling and the tank walls beginning when the wall temperature was equal or below the dew point temperature of the vapor mixture composition in the ullage. The model considers a vented fuel tank that exchanges ullage contents with ambient air upon changes in pressure between the ullage and the environment surrounding the fuel tank.

\section{DEFINITION OF FLAMMABILITY}

The lower explosive limit (LEL) of Jet $A$ can be determined by the following equation:

$$
L E L, p p m C_{3} H_{8}=F A R_{L E L}\left(\frac{M W_{\text {Air }}}{M W_{\text {Vapor }}}\right) \times C R \times 10^{6}
$$

For Jet $A$, the fuel-air mass ratio at the $L E L$ value $\left(F R_{L E L}\right)$ is approximately 0.03 [10]. The carbon ratio (CR) in this equation is defined as the ratio of carbon atoms in the fuel vapor to those in propane. A representative composition of Jet $A$ fuel vapor can be found in Sagebiel's work [11] to be $\mathrm{C}_{9.58} \mathrm{H}_{17.2}$. This gives a molecular weight of the fuel vapor $\left(\mathrm{MW}_{\text {vapor }}\right)$ of 132.4 $\mathrm{g} / \mathrm{mol}$ and a CR value of approximately 0.31 . Using a value of $28.84 \mathrm{~g} / \mathrm{mol}$ as the molecular weight of air produces an approximate value of $2.1 \% \mathrm{C}_{3} \mathrm{H}_{8}$ for the LEL.

Given these calculations and the LOC results from reference 1, a flammable vapor environment can be defined as an environment in which the THC is greater that $2.1 \% \mathrm{C}_{3} \mathrm{H}_{8}$ (and lower than the determined upper flammability limit) and in which the oxygen concentration is greater than $12 \% \mathrm{O}_{2}$.
Model data was developed and presented for both flight test comparisons as well as with a representative commercial transport flight cycle. This provided for a validation of both models, as well as an illustration of the capabilities of the combined modeling techniques.

\section{COMPARISON OF MODELS WITH TEST RESULTS}

Comparisons of both the inerting model and flammability model were made with flight test data acquired from the NASA 747 SCA test aircraft. Additionally, the flammability calculations were validated against a scale test article in a laboratory environmental chamber.

Comparisons of the multiple-bay inerting model with measured data from a Boeing 747 CWT ground inerting test is given in figure 5 . The model data illustrates good agreement with aircraft data and is a marked improvement over the analytical data presented in reference 3 . The improvement was made by using data from a single, previous test to improve the mass flow split ratios from bay to bay, which were originally based on flow area in between each bay. This data did, however, illustrate poor agreement in bay 6 , which is the bay in which the NEA is deposited. This was attributed to poor mixing of the deposited gas on the aircraft, which causes a biased (high) oxygen concentration reading. Apparently, as the mixed ullage gas passed from bay to bay, vertical mixing was quickly restored.

Figure 6 illustrates a comparison of inerting model results for inerting of the CWT of the NASA 747 test aircraft during descent. The results illustrate good agreement with the most critical data (bays 1, 2, and 3), although bay 4 illustrates significant deviation from the measured flight test results. Bay 4 was identified in previous work as being difficult to model. This is exacerbated by the fact that it is small, and therefore, the resulting oxygen concentration is sensitive to flow in and out of the bay.

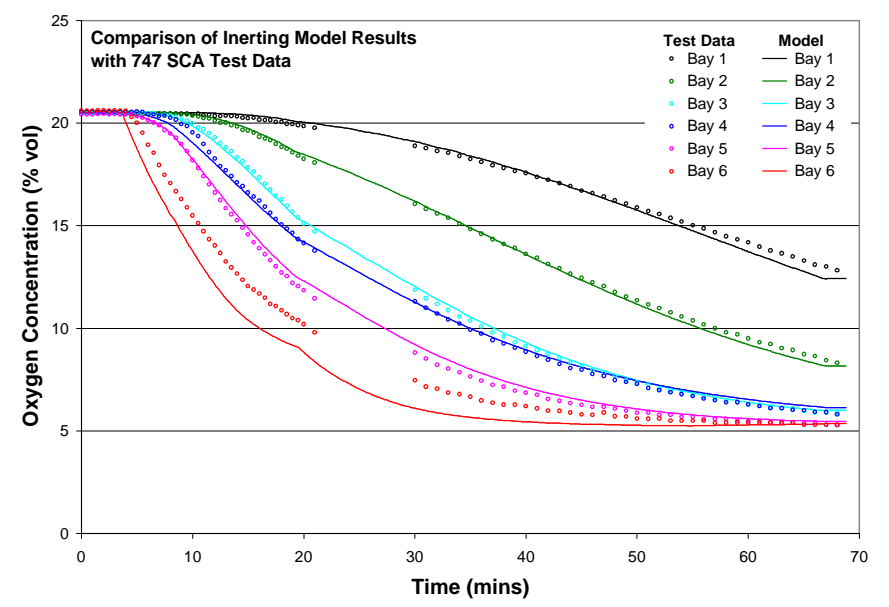

Figure 5: Comparison of Inerting Model Data With Aircraft Ground Test Results 


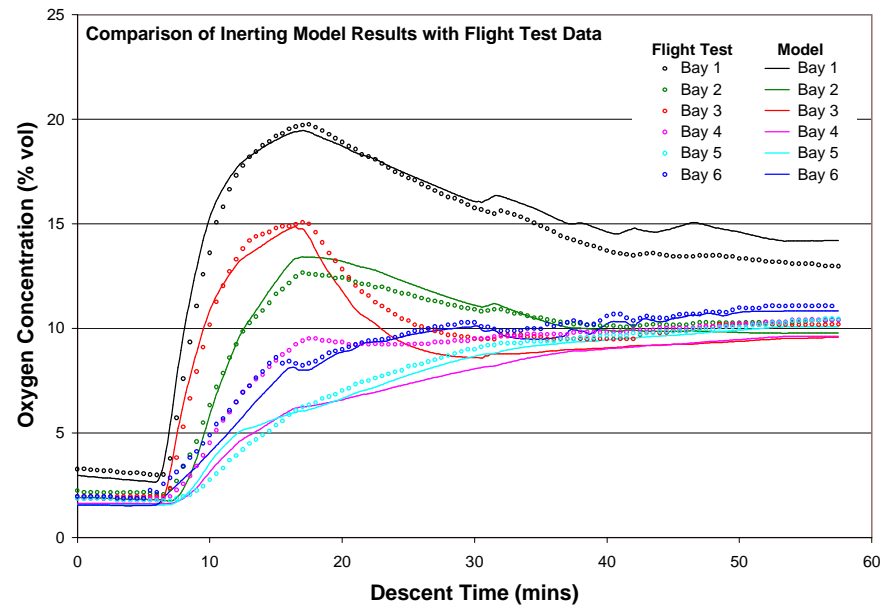

Figure 6: Comparison of In-Flight Inerting Model Data From Descent With Flight Test Results

Figure 7 depicts an experiment performed in an altitude chamber with the simulated aircraft fuel tank experiencing varying ambient conditions similar to those encountered by an in-flight aircraft. The vaporization model was used to calculate the THC using the temperature and pressure data measured during the experiment. The fuel used in the experiment had a measured flash point of $117^{\circ} \mathrm{F}$, therefore, two characterized fuel types from reference 2 were chosen with similar flash points, $115^{\circ}$ and $120^{\circ} \mathrm{F}$, for use in the model in order to "bracket" the measured flash point and THC. Intermittently measured THC is indicated by the blue dots, while the calculated THCs are indicated by the red and green curves. It is apparent that the calculated values are in good agreement with the measured values, demonstrating that the model calculations have reasonable accuracy for fuel vaporizing in a vented fuel tank under varying ambient conditions.

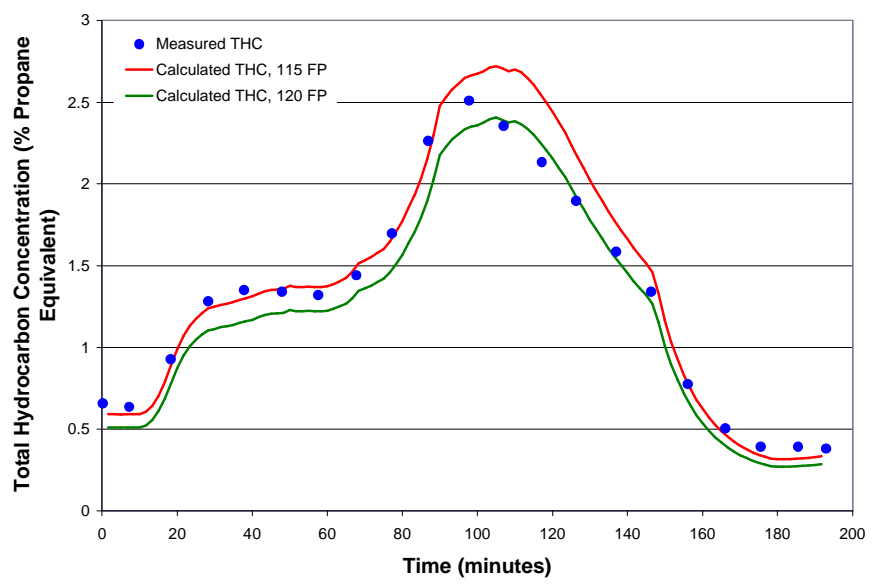

Figure 7: Comparison of Flammability Vaporization Model With Laboratory Model Validation Tests
Figure 8 shows the measured and computed CWT THC results, using the flammability vaporization model, with all systems running on the ground onboard the NASA 747 SCA test aircraft. The model was run using two different flash point fuels: $130^{\circ}$ and $135^{\circ} \mathrm{F}$. The actual flash point of the test fuel was measured as $131^{\circ} \mathrm{F}$. As expected, the computed results closely bracket the measured data, thus providing confidence in the model's ability to accurately track the THC evolution in the CWT.

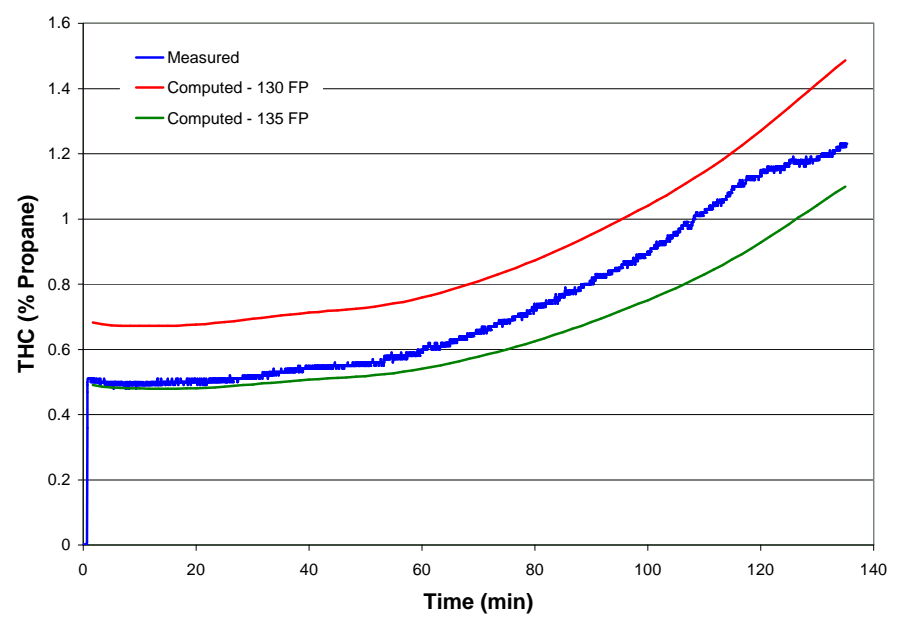

Figure 8: Comparison of Flammability Vaporization Model With NASA 747 SCA Ground Test Data

Figure 9 depicts both measured and computed CWT THC levels during one of the NASA 747 SCA flight tests. Flash point measurements of the fuel in use were recorded and correlated to fuel compositions given by Woodrow [9] of fuels with the same flash point to ensure accurate computations. Pressure data from the flight test was modified to remove any low-level, highfrequency fluctuations observed in flight, as these were found to have adverse effects on the results.

It is evident from figure 9 that the model closely predicts the general trend of hydrocarbon evolution in the fuel tank. The magnitude of the THC at cruise altitude, however, is overestimated by the model. It is believed that this is attributable to differences in the ambient pressure readings and the tank pressure due to vent flow. 


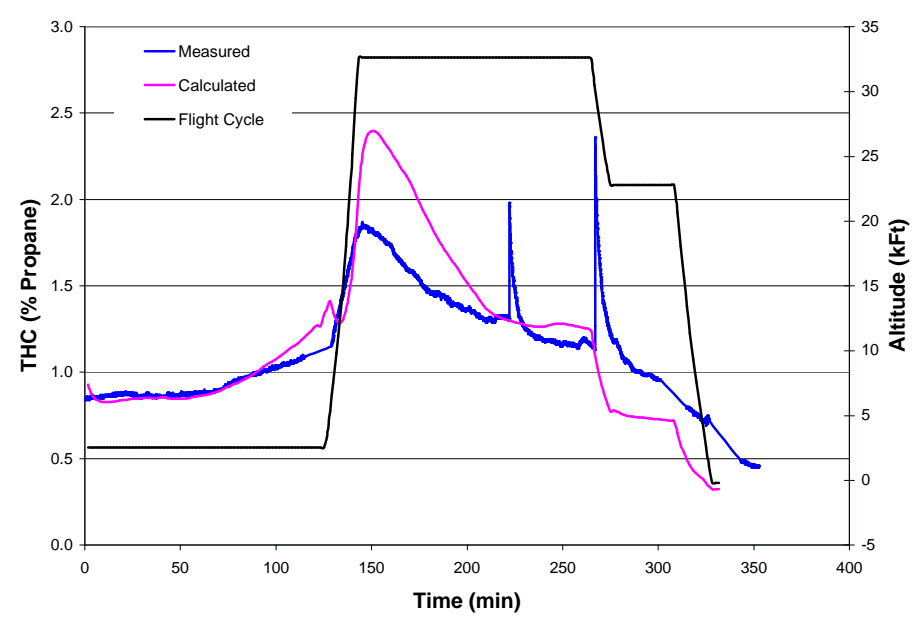

Figure 9: Comparison of Flammability Vaporization Model With NASA 747 SCA Flight Test Data

\section{REPRESENTATIVE FLIGHT MODELING RESULTS}

Figure 10 depicts the model input data for a representative Boeing 747 flight cycle developed using measured flight test data and knowledge of commercial transport aircraft operations. The inerting system used for this modeling exercise is larger than the inerting system employed during flight testing to be more representative of a certified flammability reduction system as conceived today. The aircraft CWT temperatures shown were estimated, given similar flight test data. The inerting model assumes a single deposit system with a half blocked vent system as employed on the previously discussed FAA flight test. The fuel tank wall temperature is an approximation of the four-wall composite average also observed during the FAA flight test.

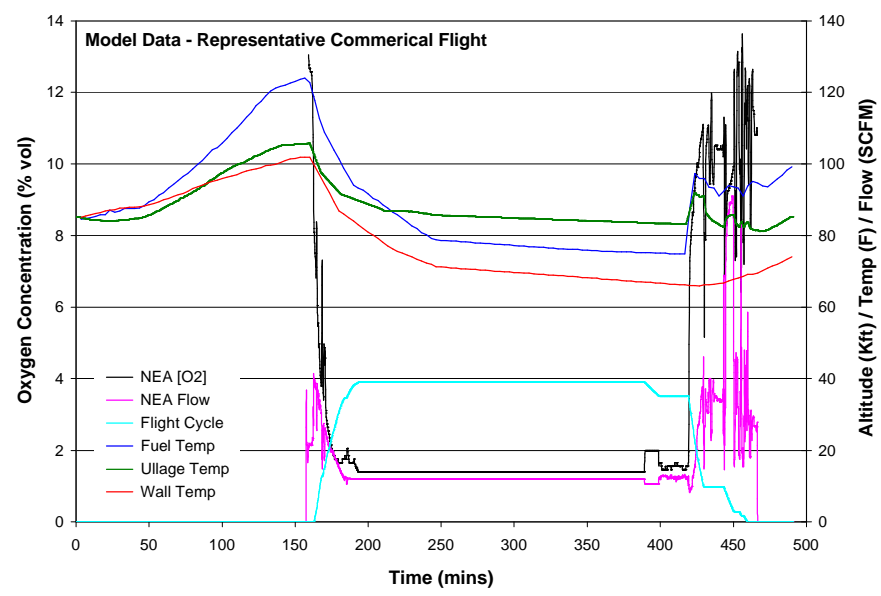

Figure 10: Flight Cycle Data With Inerting System Performance Used to Model Fuel Tank Ullage for the Representative Flight
Figure 11 gives the results of both the inerting and flammability models. During descent, the oxygen concentration in the worst bay of the fuel tank peaks at about 18 percent, well above the LOC of 12 percent. This illustrates an issue with a single NEA deposit for both the takeoff/cruise and the descent portion of flight in a complex, multiple compartment fuel tank. The overall average oxygen concentration of the ullage, however, remained well below 12 percent oxygen by volume.

The THC peaks at the start of cruise flight, which is typical of observed models and measured flammability data. As temperatures inside the tank decrease in cruise flight, flammability decreases due to fuel vapor condensation. During descent, cold temperatures combined with air entering the tank causes a drastic decrease in flammability, as shown by the total hydrocarbon results. The figure indicates that in this simulation, the CWT THC is equal to or above the LEL of 2.1 percent propane equivalent during ascent and cruise for a total exposure time of about 200 minutes ( 3 hours 20 minutes). The fuel tank would be considered flammable during this time if the oxygen concentration in the ullage gas were above the LOC of 12 percent $\mathrm{O}_{2}$. However, as indicated by the colored curves in figure 11, the oxygen concentration in all of the bays is well below 12 percent $\mathrm{O}_{2}$ for the entire length of time that the ullage hydrocarbon concentration is above 2.1 percent, thereby maintaining a nonflammable environment within the CWT throughout the entire flight cycle.

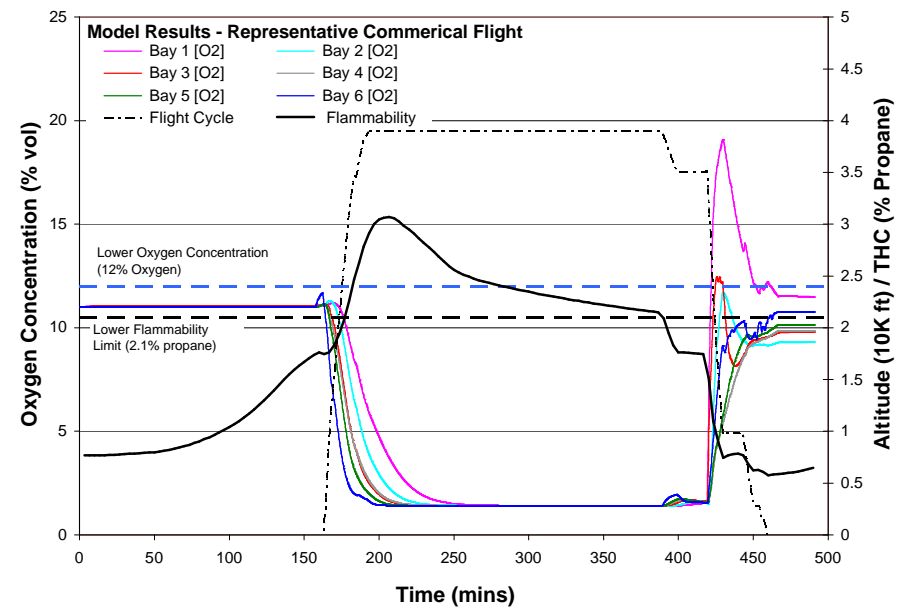

Figure 11: Illustration of Flammability Using FAA Models on a Representative Commercial Transport Flight

\section{CONCLUSION}

The FAA-developed ullage models predict oxygen concentration and $\mathrm{THC}$ trends well when compared to measured flight test data. Measured THC peak values compare fair with predicted model results, but additional work is needed to improve upon the predictive capabilities of both the FAA flammability and oxygen concentration models. 
The FAA developed a representative Boeing 747 flight cycle and used the models to predict flammability exposure for the given ullage. Results indicated the tank would not be exposed to flammable conditions during the developed flight profile and represented inerting system, even though part of the tank ullage did achieve oxygen concentration levels of approximately 18 percent during descent.

\section{ACKNOWLEDGMENTS}

Acknowledgment is given to NASA Johnson Space Center flight operations and particularly the zero-g test personnel for providing test facilities and assisting with test operation and equipment.

\section{REFERENCES}

1. Summer, S.M., "Limiting Oxygen Concentration Required to Inert Jet Fuel Vapors at Reduced Fuel Tank Pressures-Final Phase," FAA Report DOT/FAA/AR-04/8, August 2004.

2. Seibold, D.W., "Development and Evaluation of an Airplane Fuel Tank Ullage Composition Model, Volume I-Airplane Fuel Tank Ullage Computer Model," Aero Propulsion Laboratory Report AFWALTR-87-2060, October 1987.

3. Cavage, William M., "Modeling Inert Gas Distribution in Commercial Transport Aircraft Fuel Tanks," AIAA Conference Paper 2002-3032, June 2002.

4. Burns, Michael and Cavage, William M., "A Description and Analysis of the FAA Onboard Oxygen Analysis System," FAA Report DOT/FAA/AR-TN03/52, June 2003.

5. Burns, Michael et. al., "Evaluation of Fuel Tank Flammability and the FAA Inerting System on the NASA 747 SCA," FAA Report DOT/FAA/AR-04/41, December 2004.

6. Ochs, R.I. "Vaporization of JP-8 Jet Fuel in a Simulated Aircraft Fuel Tank Under Varying Ambient Conditions," M.S. Thesis, Rutgers University, May 2005.

7. Cavage, William M. and Bowman, Timothy, "Modeling In-Flight Inert Gas Distribution in a 747 Center Wing Fuel Tank," AIAA Conference Paper 2005-4906, June 2005.

8. Polymeropoulos, C.E. and Ochs, R.I. "Jet A Vaporization in a Simulated Aircraft Fuel Tank," presented at the Fourth International Aircraft Fire and Cabin Research Conference, Lisbon, Portugal, November 15-18, 2004.

9. Woodrow, J.E., "The Laboratory Characterization of Jet Fuel Vapor and Liquid," Energy and Fuels, 2003, 17:216-224.

10. Fuel Flammability Task Group, "A Review of the Flammability Hazard of Jet A Fuel Vapor in Civil Transport Aircraft Fuel Tanks," FAA Report DOT/FAA/AR-98/26, June 1998.

11. Sagebiel, J.C., "Sampling and Analysis of Vapors From the Center Wing Tank of a Test Boeing 747-
100 Aircraft," NTSB Docket No. SA-516, Exhibit No. 20G, 1997.

\section{CONTACT}

William M. Cavage: William.M.Cavage@faa.gov

Steven M. Summer: Steven.Summer@faa.gov

Robert I. Ochs: Robert.CTR.Ochs@faa.gov

C. E. Polymeropolous: poly@jove.rutgers.edu 